\title{
Local administration of bicuculline into the ventrolateral and medial preoptic nuclei modifies sleep and maternal behavior in lactating rats.
}

Luciana Benedetto ${ }^{*}$, Mayda Rivas ${ }^{a}$, Florencia Peña ${ }^{a}$, Diego Serantes ${ }^{a}$, Annabel Ferreira ${ }^{b}$ and Pablo Torterolo ${ }^{a}$

a Departamento de Fisiología, Facultad de Medicina, Universidad de la República, Montevideo, Uruguay.

b Sección de Fisiología y Nutrición, Facultad de Ciencias, Universidad de la República, Montevideo, Uruguay.

* Please address correspondence to:

Dr. Luciana Benedetto

Departamento de Fisiología, Facultad de Medicina, Universidad de la República,

General Flores 2125, 11800 Montevideo, Uruguay.

TEL: + (598) 2924-3414 x 3232. E-mail: lbenedet@fmed.edu.uy 


\section{Abstract}

The preoptic area (POA) is a brain structure classically involved in a wide variety of animal behavior including sleep and maternal care. In the current study, we evaluate the specific effect of disinhibition of two specific regions of the POA, the medial POA nucleus (mPOA) and the ventrolateral POA area (VLPO) on sleep and maternal behavior in lactating rats. For this purpose, mother rats on postpartum day 1 (PPD1) were implanted for polysomnographic recordings and with bilateral cannulae either in the MPOA or in the VLPO. The rats were tested for sleep and maternal behavior on PPD4-8 after the infusion of the GABA-A antagonist, bicuculline $(0,10$ or $30 \mathrm{ng} / 0.2 \mu \mathrm{l} /$ side $)$. Infusion of bicuculline into the $\mathrm{mPOA}$ augmented retrieving and nest building behaviors and reduced both nursing and milk ejections but had almost no effect on sleep. When bicuculine was microinjected into the VLPO, the rats significantly increase the number of retrievings and mouthings and reduced the nursing time without changes in milk ejections, which was associated with an increase in wakefulness and a reduction in light sleep.

Our results show that disinhibition of the mPOA, a key area in the control of maternal behavior, increased active maternal behaviors and reduced nursing without affecting wakefulness or sleep time. In contrast, the enhancement of some active maternal behaviors when the drug was infused into the VLPO, a sleep-promoting area, with a concomitant increase in wakefulness suggests that mother rats devote this additional waking time in the active maternal care of the pups. We hypothesize that maternal behavior changes after bicuculine microinjection into the VLPO is 
caused by a reduction in the sleep drive, rather than a direct effect on maternal behavior.

Keywords: preoptic area; postpartum; wakefulness, nursing, NREM, REM

\section{Introduction}

The preoptic area $(\mathrm{POA})$ has been recognized as the key sleep-promoting center almost one century ago [1]. Within this area, both the medial preoptic area (mPOA) $[2,3]$ and especially the ventrolateral preoptic area (VLPO) $[4,5]$ have been extensively related to the generation and maintenance of sleep. However, the role of these areas in the control of sleep seems to differ [6-8]. For instance, Sryvidya et al. (2006) reported that while the destruction of neurons within the mPOA reduces both NREM and REM sleep, the same lesions in VLPO only affect NREM sleep in male rats [6]. Since the brain of the mother rat, and specifically the POA, undergoes great anatomical and functional changes throughout the postpartum period [9-13], it could be speculated that the role of the MPOA and the VLPO on sleep and waking behavior may change during this period.

The mPOA has been postulated as the key component in the coordination and integration of maternal behavior in virtually all mammals [14]. The mPOA contains receptors for hormones, neurotransmitters and neuromodulators involved in the rapid onset of maternal behavior after parturition [15-19]. While other brain 
areas have also been implicated in the control of maternal behavior, as far as we know, there are no studies that evaluated the role VLPO in this behavior.

It has been reported a close relationship between maternal behavior and sleep [20]. Lactating rats exhibit a unique pattern of sleep [21], due in part to accomplish the maternal care of the pups. In this sense, we showed that rats mostly sleep while nursing [22]. Thus, it would be possible to speculate that sleeping areas could indirectly, through promoting or reducing sleep, modify maternal behavior.

The POA contains neurons that use GABA as a neurotransmitter and expresses GABA-A receptors that has been related to sleep [7, 8, 23-25]. In this sense, Mendelson et al. have shown that triazolam, a GABA-A agonist, promotes NREM sleep within the mPOA [8], but this drug at the same dose did no alter sleep when microinjected into the VLPO of male rats [7]. On the other hand, Arrati et al (2006) show that the GABA-A receptor agonist, muscimol, injected in the mPOA, produced dose-dependent deficits in most active components of maternal behavior [26].

As microinjections of GABA-A receptor agonists into the mPOA promote NREM sleep in male rats [7, 8], and decrease active maternal behaviors in postpartum rats [26], we hypothesize that bicuculline (BIC), a GABA-A receptor antagonist, may decrease sleep and nursing and promote active maternal behaviors when injected in this area. Despite the lack of studies concerning the role of GABA in VLPO in the control of maternal behavior, given the importance of this nucleus in sleep regulation $[4,5]$ and the close relationship between sleep and maternal 
behavior $[22,27]$, we can speculate that the disinhibition produced by BIC in this area may also decrease sleep and reduce nursing behavior.

In order to explore these hypotheses, in the present report we aimed to determine the effect produced by perfusion of BIC into the MPOA and VLPO on sleep and maternal behavior in lactating rats.

\section{Methods}

\subsection{Animals and housing}

Twenty primiparous Wistar female rats $(250-320 \mathrm{~g})$ and their pups were used in this study. All animal use and experimental procedures were in strict accordance with the "Guide to the care and use of laboratory animals" (8th edition, National Academy Press, Washington D.C., 2011) and approved by the Institutional Animal Care Committee. All efforts were made to minimize the number of animals used and their suffering.

Two days before giving birth, pregnant females were housed individually in transparent cages $(40 \times 30 \times 20 \mathrm{~cm})$ containing shredded paper towels as nestbuilding material. The animals were placed in a temperature-controlled $\left(22 \pm 1^{\circ} \mathrm{C}\right)$, sound-proof and electromagnetically shielded recording chamber fitted with slip rings and cable connectors for bioelectrical recordings, under a 12-h light/dark cycle (lights on at 6:00 am), with ad libitum access to food and water. On postpartum day 
1 (PPD1, birth = day 0), litters were culled to four female and four male pups per mother.

\subsection{Stereotaxic surgery}

The surgical procedures were similar as previous studies of our group [27, 28]. On the morning of PPD1, females were anesthetized with a mixture of ketamine/ xylazine/ acepromazine maleate (80/2.8/2.0 mg/kg, i.p.). Using a stereotaxic device, female rats were bilaterally implanted with a 22-gauge stainless steel guide cannulae with a dummy cannula (Plastic One, Roanoke, VA) aimed $2 \mathrm{~mm}$ dorsal to the mPOA: AP $-0.5 \mathrm{~mm}$ (from Bregma); $\mathrm{ML} \pm 0.5 \mathrm{~mm}$; DV $-6.5 \mathrm{~mm}$ (from skull surface) or the VLPO: AP -0.5 mm (from Bregma); ML $\pm 1.0 \mathrm{~mm}$; DV -6.8 mm (from skull surface, according to [29]). In addition, cortical electroencephalogram (EEG) electrodes and dorsal neck muscle electromyogram (EMG) electrodes were implanted for the assessment of sleep and wakefulness (W) states. Recording electrodes for EEG were placed in the frontal cortex $(A P=+4.0 ; M L=2.0)$, parietal cortex $(A P=-4.0$, $M L=2.0)$, occipital cortex $(A P=-7.0, M L=3.0)$, and over the cerebellum as a reference electrode $(A P=-11.0, M L=0.0)$ [29]. Two additional stainless-steel screws were implanted into the skull as anchors. All electrodes were soldered to a six-pin connector. The connector and the guide cannulae were cemented to the skull using dental acrylic.

A pre-surgery single dose of ketoprofen $(5 \mathrm{mg} / \mathrm{kg}$, s.c.) was used to reduce pain. In addition, topic antibiotic (Crema 6A, Labyes) was applied into the surgery 
injury and sterile $0.9 \%$ saline (10 ml/kg, s.c.) was administrated post-surgery to prevent dehydration during recovery.

During surgery, pups were maintained in their home cage under a heat lamp. Immediately after surgery, each mother was reunited with her pups in the home cage located in the recording chamber until the end of the experiments.

\subsection{Experimental design}

Mother rats were randomly assigned to one of two independent groups: VLPO or mPOA treatment. All experiments were performed between PPD4-8 during the light phase. Before experiments began, a baseline recording session was performed to corroborate that all sleep parameters and maternal behaviors were adequate. Each animal received 3 microinjections: $10,30 \mathrm{ng}$ of $\mathrm{BIC}$ and vehicle in a counterbalanced design. The following day after the microinjections, no experiments were performed.

\subsection{Drug}

BIC (Phoenix Pharmaceuticals Inc., Belmont, CA, \#070-47) was dissolved in sterile $0.9 \%$ saline to obtain a final concentration of 50 and $150 \mathrm{ng} / \mu \mathrm{l}$. Aliquots for these doses were prepared in advance, frozen at - $20^{\circ} \mathrm{C}$, and thawed immediately before use.

\subsection{Microinjection procedure}

Females were bilaterally microinjected into the MPOA or the VLPO with either $10 \mathrm{ng}$ of $\mathrm{BIC}\left(\mathrm{BIC}_{10}\right), 30 \mathrm{ng}$ of $\mathrm{BIC}\left(\mathrm{BIC}_{30}\right)$ dissolved in $200 \mathrm{nl}$ of saline, or the same 
volume of saline over a period of 2 minutes, with the injection cannulae (28 gauge) extending $2 \mathrm{~mm}$ beyond the tip of guide cannulae, using a constant-rate infusion pump (Harvard apparatus, USA). The administration cannulae were left in place for an additional minute to allow for the diffusion of the drug. Similar doses were employed in previous studies [30, 31].

\subsection{Experimental sessions}

We used the same experimental protocol in previous studies (for details see [27]). Briefly, pups were removed from the maternal cage for three hours. Before the end of maternal separation, the entire litter was weighed and concomitantly, the microinjection procedure was performed. Immediately after, the mother rat was connected to the recoding system. Once the maternal separation was completed, the pups were scattered in the mothers' home cage opposite to the nest and the polysomnographic recording and collecting maternal behavior data using a video camera were initiated. After a 4-hour-recodring session, the mother rat was disconnected from the recording device and the entire litter was weighed again [27].

\subsection{Maternal behavior}

Maternal behavior was tested for 30 minutes, as previously described [32]. Accordingly, the number of the following active maternal behaviors measured were: retrieval of the pups to the nest, mouthing (oral re-arrangement of a pup within the nest), licking (corporal and anogenital) and nest building. Also, the latencies to group the entire litter into the nest were measured. In addition, the latencies (first episode $\geq 2$ min in duration) and durations of passive behaviors, including hovering over the 
pups, nursing (kyphotic and supine postures), as well as the total time in contact with the pups (hover over plus nursing) were assessed. In addition, the number of milk ejections was indirectly quantified through the stretching behavior of the pups [33, 34]. The litter weight gain (LWG) was used as an indirect measurement of the amount of ejected milk [27, 35], calculated as the percentage of the difference between the final and initial weight of the entire litter [36].

Any behavior that was not initiated or completed within the 30-min test period was given a latency of $1800 \mathrm{~s}$. The number of eating and self-grooming behaviors was also annotated [27, 32].

\subsection{Sleep recording}

Bioelectric signals were amplified (x1000), filtered $(0.1-500 \mathrm{~Hz})$, sampled (1024 Hz, 16 bits) and stored in a PC for further analysis using the Spike 2 software. The states of light sleep (LS), slow wave sleep (SWS), REM sleep and W were determined in 5-seconds epochs with standard criteria [22, 27, 28, 36]. Additionally, the intermediate stage was also distinguished (IS, sleep spindles combined with theta activity $[27,37])$.

Total time spent in W, LS, SWS, NREM sleep (LS+SWS), IS and REM sleep over the total recording time and each hour were analyzed. To have a representative analysis of sleep during the maternal behavior test, we also analyzed sleep and $\mathrm{W}$ values during the first half hour. In addition, sleep latencies (first episodes $\geq 20$ seconds from the beginning of the recordings), number, and duration of episodes of each state were calculated. 
Although classical criteria for NREM analysis include LS, SWS and IS, previous data [27] and recent unpublished data from our laboratory strongly suggest that IS should be considered an independent state, and must not be classified as NREM sleep.

\subsection{EEG spectral power analysis}

Digitized, raw EEG signals in prefrontal and parietal channels were exported from Spike2 software into MATLAB at $1024 \mathrm{~Hz}$ sampling frequency. The power spectrum was obtained by means of the pwelch built-in function in MATLAB (parameters: window $=1024$, noverlap $=[]$, fs $=1024$, nfft $=1024)$, which corresponds to 1-s sliding windows with half-window overlap, and a frequency resolution of $1 \mathrm{~Hz}$ [38]. All spectra were normalized to obtain the relative power by dividing the power value of each frequency by the sum across frequencies (total power). Because notch filters were applied to EEG channels in some recordings, power analysis was performed up to $45 \mathrm{~Hz}$. EEG spectral analysis was then conducted during the first half hour, and for the total recording time for each frequency band $(\delta[1-4 \mathrm{~Hz}], \theta[5-9 \mathrm{~Hz}], \sigma[10-15 \mathrm{~Hz}] \beta[15-30]$ and $\mathrm{\gamma}[30-45 \mathrm{~Hz}$. For each animal in each treatment group, the mean power spectrum in each behavioral state (W, LS, SWS, IS and REM) was obtained by averaging the power spectra across all available windows in prefrontal and parietal cortices.

As most animals did not present neither IS nor REM sleep during the first half hour, these states were removed from the analysis in this time-window.

\subsection{Histological verification of microinjection sites}


At the end of the experiment, each animal was euthanized with an overdose of ketamine/ xylazine mixture (i.p.), perfused with 4\% paraformaldehyde, and their brains were removed for histological processing. Thereafter, the brains were cut in $150 \mu \mathrm{m}$ coronal sections with a vibratome. The location of mPOA and VLPO microinjection sites were verified according to [29].

\subsection{Statistics}

Data from maternal parameters did not follow a normal distribution (Kolmogorov-Smirnov test, $\mathrm{p}<0.05)$. Thus, maternal parameters are presented as median \pm SIQR (semi-interquartile range) and statistical differences between experimental and control groups were evaluated using Friedman test followed by a post hoc comparison using Wilcoxon signed-rank test. Comparisons between VLPO and mPOA control groups were analyzed using Mann Whitney U test [39].

As sleep parameters and power spectrum of EEG data follow a normal distribution (Kolmogorov-Smirnov test, $p>0.05$ ), values are presented as mean \pm S.E.M. (standard error) and the statistical significance of the differences between controls versus drug effects were evaluated utilizing one-way repeated measures (ANOVA) followed by Tukey post hoc test. Comparisons between VLPO and mPOA control groups were analyzed using Student T test for independent samples.

The criterion used to discard the null hypotheses in all cases was $p<0.05$.

\section{Results}

\subsection{Sites of injection}


As shown in Figure 1A, the microinjection sites in seven rats were located within the mPOA between -0.24 and $-0.48 \mathrm{~mm}$ from Bregma, based on examination of cannulae tracks in histological sections [29]. Two animals were excluded from the data analysis due to misplaced cannulae. Figure 1B shows the microinjection site of eight rats located within the VLPO. Three rats were excluded from the data analysis due to the cannulae were out of the VLPO borders.

\subsection{Bicuculline effects on mPOA}

\subsubsection{Maternal behavior}

Maternal behavior components after the microinjection of vehicle, $\mathrm{BIC}_{10}$ and $\mathrm{BIC}_{30}$ within the mPOA are shown in Figure 2 and Table 1.

The microinjection of $\mathrm{BIC}_{10}$ into the mPOA significantly increased the number of pups retrieved to the nest in comparison with the infusion of saline $\left(T_{7}=1.0, p=\right.$ 0.046), whereas $\mathrm{BIC}_{30}$ increased the number of nest building $\left(T_{7}=1.0, p=0.027\right.$, see Figure 2). None of the other active maternal behaviors were affected by the drug (see Figure 2).

Compared to saline microinjections, $\mathrm{BIC}_{30}$ decreased the time total time in contact with the pups $\left(T_{7}=0.0 ; p=0.017\right)$, reduced the time hovering over the pups $\left(T_{7}=1.0, p=0.027\right)$ and the number of milk ejections $\left(T_{7}=0.0 ; p=0.027\right)$. In addition, $\mathrm{BIC}_{30}$ decreased the time the females nurse their pups compared to control group $\left(T_{7}=0.0 ; p=0.017\right)$ and to the lowest dose $\left(T_{7}=2.0 ; 0.042\right.$, see Table 1$)$. 
The highest dose of BIC increased the latency to begin nursing compared to saline microinjection $\left(T_{7}=1.0, p=0.027\right)$ and to the lowest dose $\left(T_{7}=1.0, p=0.027\right.$, see Table 1).

Non-maternal behaviors during the maternal behavioral are shown in Supplementary Table S1. Neither eating nor self-grooming were significant different among groups.

\subsubsection{Sleep}

Statistical comparisons were non-significant for most sleep parameters (see Figure 3 and Table 2), except for the total IS recording time that was significantly different among groups $(F(2,12)=3.947, p=0.048)$; post hoc analysis did not reach significant differences, but time in IS tended to be higher after $\mathrm{BIC}_{10}$ treatment compared to saline $(\mathrm{p}=0.082)$ and $\mathrm{BIC}_{30}(\mathrm{p}=0.069)$. Additionally, when analyzed the first half hour and each hour independently, only the time spent in REM sleep during the second hour differ among groups $(F(2,12)=4.255, p=0.040)$, specifically reduced in $\mathrm{BIC}_{30}$ compared to control treatment $(\mathrm{p}=0.032)$. The number of episodes, frequency and its duration, as well as latencies for each behavioral stage remained unchanged among groups (see Table 2).

The power spectrum profiles in different behavioral stages are shown in Figure 4 and Supplementary Figure S1, for the total recording time and the first half hour respectively, where it is evidenced that no differences were found in any frequency band power, cortex or behavioral stage among groups, neither in the total recording time nor in the first half hour. 


\subsection{Bicuculline effects on VLPO}

\subsubsection{Maternal behavior}

As shown in Figure 2, after $\mathrm{BIC}_{30}$ microinjection into the VLPO, the number of pups retrievings increased compared to control microinjections $\left(T_{8}=0.0, p=0.011\right)$. Also, the number of mouthings augmented at this dose compared to saline group $\left(T_{8}=3.5, p=0.042\right)$. However, the number of anogenital licking decreased at both doses compared to saline microinjections $\left(\mathrm{BIC}_{10}: \mathrm{T}_{8}=0.0, \mathrm{p}=0.011 ; \mathrm{BIC}_{30}: \mathrm{T}_{8}=0.0\right.$, $\mathrm{p}=0.017)$.

Most passive maternal behaviors were disrupted after the highest dose, and some of them with the lowest one (see Table 3). Specifically, the time hovering over the pups was reduced at both doses compared to vehicle values $\left(\mathrm{BIC}_{10}: \mathrm{T}_{8}=3.0, \mathrm{p}\right.$ $\left.=0.035 ; \mathrm{BIC}_{30}: \mathrm{T}_{8}=2.0, \mathrm{p}=0.025\right)$ as well as the total time in contact with the pups $\left(\mathrm{BIC}_{10}: \mathrm{T}_{8}=0.0, \mathrm{p}=0.011 ; \mathrm{BIC}_{30}: \mathrm{T}_{8}=2.0, \mathrm{p}=0.025\right)$. The total time spent in nursing the pups over the 30-minutes test was slightly decreased after the highest dose compared to vehicle $\left(T_{8}=4.0, p=0.049\right)$. Also, the latency to begin hovering over the pups $\left(\mathrm{BIC}_{10}: \mathrm{T}_{8}=2.0, \mathrm{p}=0.025 ; \mathrm{BIC}_{30}: \mathrm{T}_{8}=3.0, \mathrm{p}=0.035\right)$ and nursing $\left(\mathrm{BIC}_{10}\right.$ : $\left.\mathrm{T}_{8}=3.0, \mathrm{p}=0.035 ; \mathrm{BIC}_{30}: \mathrm{T}_{8}=3.0, \mathrm{p}=0.035\right)$ were increased after $\mathrm{BIC}$ microinjection at both doses compared to vehicle.

No other significant differences were found neither between each dose compared to vehicle group nor between $\mathrm{BIC}_{10}$ and $\mathrm{BIC}_{30}$. 
Non-maternal behaviors (self-grooming and eating) were not affected by either doses of BIC in comparison to saline microinjections (see Table S1 in Supplementary data).

As a control procedure, we compared all the maternal behavior parameters between saline microinjection into the VLPO and mPOA; no significant differences were observed.

\subsubsection{Sleep}

As depicted in Figure 5, statistical analysis over the total recording time showed significant differences in $\mathrm{W}$ time $(F(2,14)=6.342, p=0.010)$, with an increase after $\mathrm{BIC}_{30}$ compared to $\mathrm{BIC}_{10}(\mathrm{p}=0.018)$ and control values $(\mathrm{p}=0.023)$. Also, the total time spent in LS differ between groups $(F(2,14)=6.302, p=0.011)$, being reduced when comparing $\mathrm{BIC}_{10}(\mathrm{p}=0.034)$ and $\mathrm{BIC}_{30}(\mathrm{p}=0.014)$ with control group (see Figure 5). In addition, the duration of LS episodes varied among groups $(F(2,14)=9.861, p=0.002)$, where both $\mathrm{BIC}_{10}(\mathrm{p}=0.009)$ and $\mathrm{BIC}_{30}(\mathrm{p}=0.002)$ where significantly reduced compared to saline treatment (see Table 4).

The total time in SWS significantly differ among groups $(F(2,14)=4.029$, $\mathrm{p}=0.041$ ). Although this parameter tended to increase in $\mathrm{BIC}_{10}$ group compared to $\mathrm{BIC}_{30}(\mathrm{p}=0.062)$ and saline treatment $(\mathrm{p}=0.072)$, none of the post hoc analysis reached significant values.

The total time in NREM sleep differ between groups $(F(2,14)=4.198, p$ $=0.037)$. Specifically, after $\mathrm{BIC}_{30}$ microinjection this time was reduced compared to 
$\mathrm{BIC}_{10}$ treatment $(\mathrm{p}=0.045)$ and tend to be reduced when comparing to saline group $(p=0.087)$

REM values over the total recording time tended to be different among groups but did not reach significant differences $(F(2,14)=3.077, p=0.078)$. However, as shown in Table 4, the total number of REM episodes differ among groups $(F(2,14)$ $=4.380, p=0.033)$, being $\mathrm{BIC}_{30}$ reduced compared with $\mathrm{BIC}_{10}(\mathrm{p}=0.037)$ and had $\mathrm{a}$ slightly tendency to be reduced when compared to saline treatment $(p=0.091)$. In addition, the frequency of REM episodes per hour was also significantly different among groups $(\mathrm{F}(2,14)=4.380, \mathrm{p}=0.033)$, being significantly lower $\mathrm{BIC}_{30}$ compared to $\mathrm{BIC}_{10}$ treatment $(\mathrm{p}=0.038)$.

During the first half hour, when maternal behavior was tested, the time spent in W differ among groups $(F(2,14)=7.294, \mathrm{p}=0.006)$, where $\mathrm{BIC}_{10}$ treatment had less $\mathrm{W}$ compared to $\mathrm{BIC}_{30}(\mathrm{p}=0.005)$. In addition, the first half hour the time spent in LS differ among groups $(F(2,14)=11.864, p=0.000)$. Specifically, LS time was reduced after $\mathrm{BIC}_{30}$ compared to both saline $(\mathrm{p}=0.000)$ and $\mathrm{BIC}_{10}$ treatment $(\mathrm{p}$ $=0.030)$. Furthermore, SWS also was affected by BIC treatment the first half hour $(F(2,14)=5,128, p=0.021)$, being increased after $\mathrm{BIC}_{10}$ compared to saline $(\mathrm{p}=$ $0.037)$ and $\mathrm{BIC}_{30}$ treatment $(\mathrm{p}=0.037)$.

The mean power spectrum in different behavioral states during the total recording time and the first half hour were plotted in Figure 6 and Supplementary Figure S2 respectively. In particular, the theta frequency band in the prefrontal cortex during REM sleep in the total recording time was significant different among groups 
$\left(\mathrm{F}(2,14=5.131, \mathrm{p}=0.021\right.$, see Figure 6$)$. Specifically, $\mathrm{BIC}_{30}$ was significantly reduced compared to control $(p=0.049)$ and to $B_{10}$ values $(p=0.009)$. No additional differences were found in any other frequency band power among groups at any behavioral state or cortex.

As a control procedure, we compared all sleep parameters between saline microinjection into the VLPO and MPOA; no significant differences were observed in the total recording time or latencies in any of the behavioral stages.

\section{Discussion}

In the present study, we evaluated the regulation of sleep and maternal behavior after the microinjection of the GABA-A antagonist bicuculline into the mPOA and VLPO. Maternal behavior was similarly affected by BIC when applied either within the MPOA or VLPO. In addition, sleep and wakefulness values were modified when BIC was applied into the VLPO but almost unchanged by the same treatment within the mPOA.

\section{1. mPOA and maternal behavior}

The local infusion of BIC within the mPOA selectively enhanced some active components of maternal behavior, while reducing nursing behavior. Specifically, retrieving and nest building were enhanced after local delivery of BIC into the mPOA. In this sense, the GABA-A receptor agonist muscimol, microinjected in the mPOA produced a reduction of retrieving and nest building while leaving nursing intact [26]. A large body of evidence show that lesions or inactivation of mPOA $[40,41]$ and 
disruptions of its connection with the mesocorticolimbic system [42, 43] mainly affect the active components of maternal behavior such as the retrieving of the pups.

Although it was demonstrated the presence of GABA-A receptors within the mPOA [25], it is uncertain which are the neuronal phenotype and cellular localization within this area that we are antagonizing in the present report. It can be hypothesized that BIC may disinhibit either local inhibitory GABAergic interneurons or neurons that provide inhibitory input to other neural sites, allowing meaningful sensory stimulus coming from the pups activate the mPOA that project to different brain areas that stimulate maternal care of the pups [44]. In this sense, Lonstein et al. (2000) proposed that the neurons within mPOA that show elevated c-fos activity during the display of maternal behavior are either local inhibitory GABAergic interneurons or provide inhibitory input to other neural sites [45]. Otherwise, BIC can be acting directly into galaninergic neurons within the mPOA that have been demonstrated to be crucial for parenting behavior [46]. More studies are needed to assess if the impairing in retrieving is due to local mechanisms within the mPOA or to its ascending projections.

The reduction in the time devoted to nurse the pups after BIC injections may be related to the increased time invested in active maternal behavior. This result differs with that of Arrati et al (2006) showing that muscimol, microinjected in the mPOA did not affect nursing [26]. Although both drugs are GABA-A agents, and would expect opposite actions, differences in the dose or protocol may account for this discrepancy. In addition, maternal behavior is not a unitary process but rather a complex group of sequential behaviors that have their own sensory and neural 
determinants [40]. Specifically, it has been shown that nursing behavior is not primary controlled mPOA, but by brainstem-spinal areas [40, 41]. Therefore, it can be speculated that the reduction of the time devoted to nurse may be a consequence of the investment in the active care of the pups.

\subsection{VLPO and maternal behavior}

In an attempt to explore if there is an overlap in the neural networks related to sleep and maternal behavior, we evaluated maternal behavior after the blockade of GABAergic neurotransmission within the VLPO, a key area in sleep control. As expected, the increase in the time spent in wakefulness was accompanied by a decreased in nursing time without changes in milk ejections. The fact that active maternal behaviors that involve more motor activity (pup-retrieving and mouthing) increased while anogenital licking was reduced, favors the hypothesis that maternal modifications are a consequence of the difficulty to sleep. In addition, non-maternal behaviors such a self-grooming or eating were not modified. Taken together, these results suggest that the capability of mother rat to stay still in the nest is reduced, devoting her augmented waking time to the execution of maternal behaviors that do not require relative quiescence.

\section{3. mPOA and sleep}

Here we reveal almost no effect on sleep when BIC was microinjected into the mPOA nor in the EEG analysis in any of the behavioral stages. In agreement with our present data, Chari et al. (1995) found no impact on sleep after local delivery of GABA into the mPOA [47]. Nevertheless, the role of the mPOA in the regulation 
of sleep has been demonstrated using different techniques [2, 8, 48-54]. However, since the protocol and doses applied for the MPOA were the same as in the VLPO, the results suggest that the GABAergic processes that control sleep in the postpartum rat are weaker within the mPOA than in the VLPO. In this sense, it has been shown that there are sex-specific differences in GABAA receptors [55], and within the mPOA, the expression of these receptors has an important hormonal dependency [56-58]. In this sense, in regions of the forebrain and hypothalamus, the sensitivity of the GABA-A receptor to neurosteroid modulation has also been shown to vary significantly with hormonal state (for review, [59-61]). Besides, as the mPOA undergoes great anatomical changes during the postpartum period $[11,13,62]$, its functional role in sleep could be modified. Thus, the hormonal fluctuations during lactation could modify the capability of BIC administration into mPOA to modify sleep.

\subsection{VLPO and sleep}

Since Sherin et al. (1996), the VLPO has been largely established as a main brain structure in the control of sleep process [5, 28, 63-65]. However, the current data shows that the decrease in GABAergic transmission within the VLPO promotes wakefulness and reduces sleep in postpartum females, without great modifications of the EEG activity. In this sense, recent evidence show that the lateral preoptic area triggers awakening from sleep and that the waking state is accompanied with an increased in the cortical activity [66]. In addition, recent reports evidenced that chemogenetic stimulation of glutamatergic neurons induce wakefulness $[67,68]$. 
Thus, it can be postulated that BIC would directly disinhibit these glutamatergic neurons that promote wakefulness.

We also observed that perfusion of $\mathrm{BIC}_{30}$ into the VLPO decreased theta power in the prefrontal cortex during REM sleep. A possible explanation could be the regulation of the VLPO projection toward areas that desynchronize this rhythm, such as the medial raphe nucleus $[69,70]$.

\subsection{Conclusions}

In the present study, using BIC as a pharmacological tool to disinhibit the MPOA and VLPO of postpartum rats, we evaluate the role of the MPOA and VLPO on sleep and maternal behavior. The results show that BIC microinjections into the mPOA increased certain active maternal behaviors and decreased nursing without affecting sleep and wakefulness, probably as a result of changes in the mechanisms that control maternal behavior. In contrast, the same drug in the VLPO provoked an increase in some active maternal behaviors and a decrease in nursing postures together with an enhancement of wakefulness, suggesting that maternal behavior can be altered by modifying a sleep-promoting area.

\section{Acknowledgements}

We thank MSc. Joaquin Gonzalez for his technical support in EEG analysis. This work was partially supported by "Programa de Desarrollo de Ciencias Básicas (PEDECIBA)". All authors have seen and approved the manuscript, and it hasn't been accepted or published elsewhere. The authors have no competing interests. 


\section{References}

[1] Von Economo, C. Sleep as a problem of localization. J. Nerv. Ment. Dis. 1930,71:249-59.

[2] Kumar, V. M. Why the medial preoptic area is important for sleep regulation. Indian journal of physiology and pharmacology. 2004,48:137-49.

[3] Mendelson, W. B., Martin, J. V., Perlis, M., Wagner, R. Enhancement of sleep by microinjection of triazolam into the medial preoptic area. Neuropsychopharmacology. 1989,2:61-6.

[4] Sherin, J. E., Elmquist, J. K., Torrealba, F., Saper, C. B. Innervation of histaminergic tuberomammillary neurons by GABAergic and galaninergic neurons in the ventrolateral preoptic nucleus of the rat. J Neurosci. 1998,18:4705-21.

[5] Sherin, J. E., Shiromani, P. J., McCarley, R. W., Saper, C. B. Activation of ventrolateral preoptic neurons during sleep. Science (New York, N.Y. 1996,271:2169.

[6] Srividya, R., Mallick, H. N., Kumar, V. M. Differences in the effects of medial and lateral preoptic lesions on thermoregulation and sleep in rats. Neuroscience. 2006,139:853-64.

[7] Mendelson, W. B. Effects of microinjections of triazolam into the ventrolateral preoptic area on sleep in the rat. Life sciences. 1999,65:PL301-7.

[8] Mendelson, W. B., Martin, J. V. Characterization of the hypnotic effects of triazolam microinjections into the medial preoptic area. Life sciences. 1992,50:111728.

[9] Pereira, M., Morrell, J. I. The changing role of the medial preoptic area in the regulation of maternal behavior across the postpartum period: facilitation followed by inhibition. Behavioural brain research. 2009,205:238-48.

[10] Knollema, S., Brown, E. R., Vale, W., Sawchenko, P. E. Novel Hypothalamic and Preoptic Sites of Prepro-Melanin-Concentrating Hormone Messenger Ribonucleic Acid and Peptide Expression in Lactating Rats. Journal of neuroendocrinology. 1992,4 709 - 17.

[11] Rondini, T. A., Donato, J., Jr., Rodrigues Bde, C., Bittencourt, J. C., Elias, C. F. Chemical identity and connections of medial preoptic area neurons expressing melanin-concentrating hormone during lactation. Journal of chemical neuroanatomy. 2010,39:51-62.

[12] Parent, C., Wen, X., Dhir, S. K., Ryan, R., Diorio, J., Zhang, T. Y. Maternal care associates with differences in morphological complexity in the medial preoptic area. Behavioural brain research. 2017,326:22-32.

[13] Shams, S., Pawluski, J. L., Chatterjee-Chakraborty, M., Oatley, H., Mastroianni, A., Fleming, A. S. Dendritic morphology in the striatum and hypothalamus differentially exhibits experience-dependent changes in response to maternal care and early social isolation. Behavioural brain research. 2012,233:79-89.

[14] Fisher, A. E. Maternal and sexual behavior induced by intracranial chemical stimulation. Science (New York, N.Y. 1956,124:228-9. 
[15] Bakowska, J. C., Morrell, J. I. Atlas of the neurons that express mRNA for the long form of the prolactin receptor in the forebrain of the female rat. The Journal of comparative neurology. 1997,386:161-77.

[16] Champagne, F., Diorio, J., Sharma, S., Meaney, M. J. Naturally occurring variations in maternal behavior in the rat are associated with differences in estrogeninducible central oxytocin receptors. Proceedings of the National Academy of Sciences of the United States of America. 2001,98:12736-41.

[17] Insel, T. R. Regional changes in brain oxytocin receptors post-partum: timecourse and relationship to maternal behaviour. Journal of neuroendocrinology. 1990,2:539-45.

[18] Numan, M., Roach, J. K., del Cerro, M. C., Guillamon, A., Segovia, S., Sheehan, T. P., et al. Expression of intracellular progesterone receptors in rat brain during different reproductive states, and involvement in maternal behavior. Brain Res. 1999,830:358-71.

[19] Pi, X., Grattan, D. R. Expression of prolactin receptor mRNA is increased in the preoptic area of lactating rats. Endocrine. 1999,11:91-8.

[20] Voloschin, L. M., Tramezzani, J. H. Milk ejection reflex linked to slow wave sleep in nursing rats. Endocrinology. 1979,105:1202-7.

[21] Sivadas, N., Radhakrishnan, A., Aswathy, B. S., Kumar, V. M., Gulia, K. K. Dynamic changes in sleep pattern during post-partum in normal pregnancy in rat model. Behavioural brain research. 2016,320:264-74.

[22] Benedetto, L., Rivas, M., Pereira, M., Ferreira, A., Torterolo, P. A descriptive analysis of sleep and wakefulness states during maternal behaviors in postpartum rats. Archives italiennes de biologie. 2017,155:99-109.

[23] Swanson, L. W. The hypothalamus. In: Bjorklund A HT, Swanson L, ed. Handbook of Chemical Neuroanatomy. Amsterdam: Elsevier; 1987. p. 1-124.

[24] Fenelon, V. S., Herbison, A. E. In vivo regulation of specific GABAA receptor subunit messenger RNAs by increased GABA concentrations in rat brain. Neuroscience. 1996,71:661-70.

[25] Wisden, W., Laurie, D. J., Monyer, H., Seeburg, P. H. The distribution of 13 GABAA receptor subunit mRNAs in the rat brain. I. Telencephalon, diencephalon, mesencephalon. J Neurosci. 1992,12:1040-62.

[26] Arrati, P. G., Carmona, C., Dominguez, G., Beyer, C., Rosenblatt, J. S. GABA receptor agonists in the medial preoptic area and maternal behavior in lactating rats. Physiology \& behavior. 2006,87:51-65.

[27] Benedetto, L., Rivas, M., Cavelli, M., Pena, F., Monti, J., Ferreira, A., et al. Microinjection of the dopamine D2-receptor antagonist Raclopride into the medial preoptic area reduces REM sleep in lactating rats. Neuroscience letters. 2017,659:104-9.

[28] Benedetto, L., Rodriguez-Servetti, Z., Lagos, P., D'Almeida, V., Monti, J. M., Torterolo, P. Microinjection of melanin concentrating hormone into the lateral preoptic area promotes non-REM sleep in the rat. Peptides. 2013,39:11-5.

[29] Paxinos, G., Watson, C. The Rat Brain in Stereotaxic Coordinates. 5th ed. San Diego, California: Elsevier Academic Press; 2005.

[30] Perier, C., Tremblay, L., Feger, J., Hirsch, E. C. Behavioral consequences of bicuculline injection in the subthalamic nucleus and the zona incerta in rat. $J$ Neurosci. 2002,22:8711-9. 
[31] Fernandez-Guasti, A., Larsson, K., Beyer, C. GABAergic control of masculine sexual behavior. Pharmacology, biochemistry, and behavior. 1986,24:1065-70.

[32] Benedetto, L., Pereira, M., Ferreira, A., Torterolo, P. Melanin-concentrating hormone in the medial preoptic area reduces active components of maternal behavior in rats. Peptides. 2014,58C:20-5.

[33] Drewett, R. F., Trew, A. M. The milk ejection of the rat, as a stimulus and a response to the litter. Animal behaviour. 1978,26:982-7.

[34] Lincoln, D. W., Hill, A., Wakerley, J. B. The milk-ejection reflex of the rat: an intermittent function not abolished by surgical levels of anaesthesia. The Journal of endocrinology. 1973,57:459-76.

[35] Stern, J. M. Nursing posture is elicited rapidly in maternally naive, haloperidoltreated female and male rats in response to ventral trunk stimulation from active pups. Hormones and behavior. 1991,25:504-17.

[36] Peña, F., Rivas, M., Gonzalez, J., Schwarzkopf, N., Torterolo, P., Ferreira, A., et al. Sleep and maternal behavior in the postpartum rat after haloperidol and midazolam treatments. Sleep Science. 2020:78-86.

[37] Gottesmann, C. Detection of seven sleep-waking stages in the rat. Neuroscience and biobehavioral reviews. 1992,16:31-8.

[38] Mondino, A., Cavelli, M., Gonzalez, J., Osorio, L., Castro-Zaballa, S., Costa, A., et al. Power and Coherence in the EEG of the Rat: Impact of Behavioral States, Cortical Area, Lateralization and Light/Dark Phases. Clocks Sleep. 2020,2:536-56.

[39] Siegel, S. Nonparametric Statistics for the Behavioral Sciences. . New York: McGraw-Hill; 1956.

[40] Stern, J. M., Lonstein, J. S. Neural mediation of nursing and related maternal behaviors. Progress in brain research. 2001,133:263-78.

[41] Numan, M., Stolzenberg, D. S. Medial preoptic area interactions with dopamine neural systems in the control of the onset and maintenance of maternal behavior in rats. Frontiers in neuroendocrinology. 2009,30:46-64.

[42] Numan, M., Young, L. J. Neural mechanisms of mother-infant bonding and pair bonding: Similarities, differences, and broader implications. Hormones and behavior. 2015,77:98-112.

[43] Stolzenberg, D. S., Zhang, K. Y., Luskin, K., Ranker, L., Bress, J., Numan, M. Dopamine $\mathrm{D}(1)$ receptor activation of adenylyl cyclase, not phospholipase $\mathrm{C}$, in the nucleus accumbens promotes maternal behavior onset in rats. Hormones and behavior. 2009,57:96-104.

[44] Numan, M., Insel, T. R. Neuroanatomy of Maternal Behavior. In: Numan M, Insel TR, eds. The Neurobiology of Parental Behavior: Springer; 2003. p. 107-89.

[45] Lonstein, J. S., De Vries, G. J. Maternal behaviour in lactating rats stimulates cfos in glutamate decarboxylase-synthesizing neurons of the medial preoptic area, ventral bed nucleus of the stria terminalis, and ventrocaudal periaqueductal gray. Neuroscience. 2000,100:557-68.

[46] Wu, Z., Autry, A. E., Bergan, J. F., Watabe-Uchida, M., Dulac, C. G. Galanin neurons in the medial preoptic area govern parental behaviour. Nature. 2014,509:325-30.

[47] Chari, D. M., Ramesh, V., John, J., Kumar, V. M. Effect of application of gamma amino butyric acid at the medial preoptic area on sleep-wakefulness. Indian journal of physiology and pharmacology. 1995,39:299-301. 
[48] Alam, M. N., McGinty, D., Szymusiak, R. Neuronal discharge of preoptic/anterior hypothalamic thermosensitive neurons: relation to NREM sleep. The American journal of physiology. 1995,269:R1240-9.

[49] Kumar, V. M., Sharma, R., Wadhwa, S., Manchanda, S. K. Sleep-inducing function of noradrenergic fibers in the medial preoptic area. Brain research bulletin. 1993,32:153-8.

[50] Mohan Kumar, V., John, J., Govindaraju, V., Khan, N. A., Raghunathan, P. Magnetic resonance imaging of NMDA-induced lesion of the medial preoptic area and changes in sleep, temperature and sex behaviour. Neuroscience research. 1996,24:207-14.

[51] Azuma, S., Kodama, T., Honda, K., Inoue, S. State-dependent changes of extracellular glutamate in the medial preoptic area in freely behaving rats. Neuroscience letters. 1996,214:179-82.

[52] Khubchandani, M., Jagannathan, N. R., Mallick, H. N., Mohan Kumar, V. Functional MRI shows activation of the medial preoptic area during sleep. Neurolmage. 2005,26:29-35.

[53] Mendelson, W. B. Sleep induction by microinjection of pentobarbital into the medial preoptic area in rats. Life sciences. 1996,59:1821-8.

[54] Mendelson, W. B. The sleep-inducing effect of ethanol microinjection into the medial preoptic area is blocked by flumazenil. Brain Res. 2001,892:118-21.

[55] Nett, S. T., Jorge-Rivera, J. C., Myers, M., Clark, A. S., Henderson, L. P. Properties and sex-specific differences of GABAA receptors in neurons expressing gamma1 subunit mRNA in the preoptic area of the rat. J Neurophysiol. 1999,81:192203.

[56] Clark, A. S., Myers, M., Robinson, S., Chang, P., Henderson, L. P. Hormonedependent regulation of GABAA receptor gamma subunit mRNAs in sexually dimorphic regions of the rat brain. Proc Biol Sci. 1998,265:1853-9.

[57] Herbison, A. E., Heavens, R. P., Dyer, R. G. Oestrogen and noradrenaline modulate endogenous GABA release from slices of the rat medial preoptic area. Brain Res. 1989,486:195-200.

[58] Herbison, A. E., Fenelon, V. S. Estrogen regulation of GABAA receptor subunit mRNA expression in preoptic area and bed nucleus of the stria terminalis of female rat brain. J Neurosci. 1995,15:2328-37.

[59] Brussaard, A. B., Herbison, A. E. Long-term plasticity of postsynaptic GABAAreceptor function in the adult brain: insights from the oxytocin neurone. Trends in neurosciences. 2000,23:190-5.

[60] Maguire, J., Ferando, I., Simonsen, C., Mody, I. Excitability changes related to GABAA receptor plasticity during pregnancy. J Neurosci. 2009,29:9592-601.

[61] Maguire, J., Mody, I. Steroid hormone fluctuations and GABA(A)R plasticity. Psychoneuroendocrinology. 2009,34 Suppl 1:S84-90.

[62] Gomora-Arrati, P., Gonzalez-Arenas, A., Balandran-Ruiz, M. A., MendozaMagana, M. L., Gonzalez-Flores, O., Camacho-Arroyo, I. Changes in the content of GFAP in the rat brain during pregnancy and the beginning of lactation. Neuroscience letters. 2010,484:197-200.

[63] Lu, J., Greco, M. A., Shiromani, P., Saper, C. B. Effect of lesions of the ventrolateral preoptic nucleus on NREM and REM sleep. J Neurosci. 2000,20:383042. 
[64] Lombardi, F., Gomez-Extremera, M., Bernaola-Galvan, P., Vetrivelan, R., Saper, C. B., Scammell, T. E., et al. Critical Dynamics and Coupling in Bursts of Cortical Rhythms Indicate Non-Homeostatic Mechanism for Sleep-Stage Transitions and Dual Role of VLPO Neurons in Both Sleep and Wake. J Neurosci. 2019,40:17190.

[65] Gallopin, T., Luppi, P. H., Rambert, F. A., Frydman, A., Fort, P. Effect of the wake-promoting agent modafinil on sleep-promoting neurons from the ventrolateral preoptic nucleus: an in vitro pharmacologic study. Sleep. 2004,27:19-25.

[66] Yamagata, T., Kahn, M. C., Šabanović, M., Guillaumin, M. C. C., van der Vinne, V., Huang, Y.-G., et al. The role of the hypothalamus in cortical arousal and sleep homeostasis. bioRxiv. 2020:2020.05.19.104521.

[67] Mondino, A., Hambrecht-Wiedbusch, V., Li, D., York, A. K., Pal, D., Gonzalez, J., et al. Glutamatergic neurons in the preoptic hypothalamus promote wakefulness, destabilize NREM sleep, suppress REM sleep, and regulate cortical dynamics. J Neurosci. 2021.

[68] Vanini, G., Bassana, M., Mast, M., Mondino, A., Cerda, I., Phyle, M., et al. Activation of Preoptic GABAergic or Glutamatergic Neurons Modulates Sleep-Wake Architecture, but Not Anesthetic State Transitions. Curr Biol. 2020,30:779-87 e4.

[69] Behzadi, G., Kalen, P., Parvopassu, F., Wiklund, L. Afferents to the median raphe nucleus of the rat: retrograde cholera toxin and wheat germ conjugated horseradish peroxidase tracing, and selective $\mathrm{D}$-[3H]aspartate labelling of possible excitatory amino acid inputs. Neuroscience. 1990,37:77-100.

[70] Vertes, R. P., Kocsis, B. Brainstem-diencephalo-septohippocampal systems controlling the theta rhythm of the hippocampus. Neuroscience. 1997,81:893-926. 

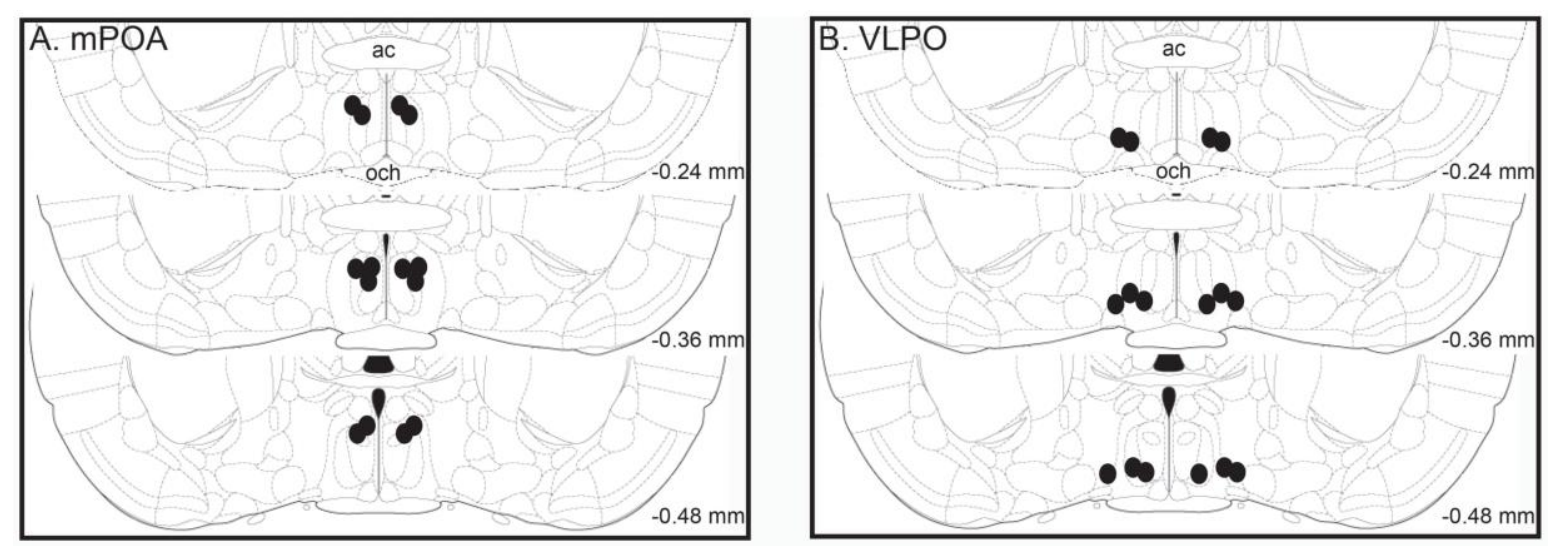

Figure 1. Microinjections sites of bicuculine at the MPOA (A) and VLPO (B).

Schematic representations of the microinjection sites in the MPOA $(n=7)$ and VLPO $(n=8)$ are indicated by black circles. The perfusion sites were recognized by the analysis of the lesions produced by the cannulae. Numbers indicate distance from Bregma. Plates were taken from the atlas of [29]. ac, anterior commissure; och, optic chiasm.

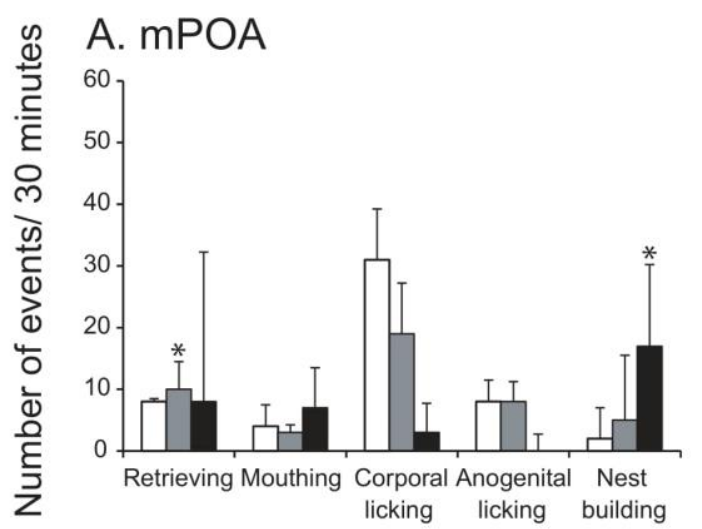

B. VLPO

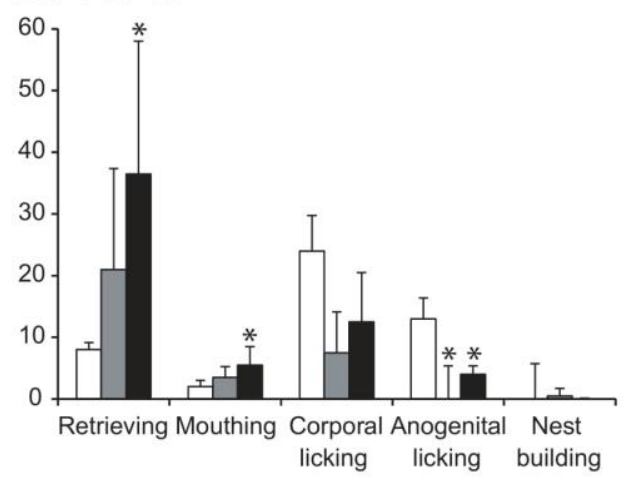

口 Saline $\quad$ BIC10 $\mathrm{ng} \quad-\mathrm{BIC} 30 \mathrm{ng}$ 
Figure 2. Effects of bicuculline (BIC) microinjections into the mPOA (A) and VLPO (B) on active components of maternal behavior. Graphic charts show the median \pm SIQR (semi-interquartile range) of the number of different active maternal responses in a 30-minute-maternal test after bilateral administration of saline and BIC (10 and $30 \mathrm{ng}$ ) into the MPOA and VLPO. Intra-group differences were determined by Friedman followed by Wilcoxon matched-pair signed-ranks test; significant differences compared to control group are indicated by asterisks ${ }^{*}, p<$ $0.05)$. 
Wakefulness

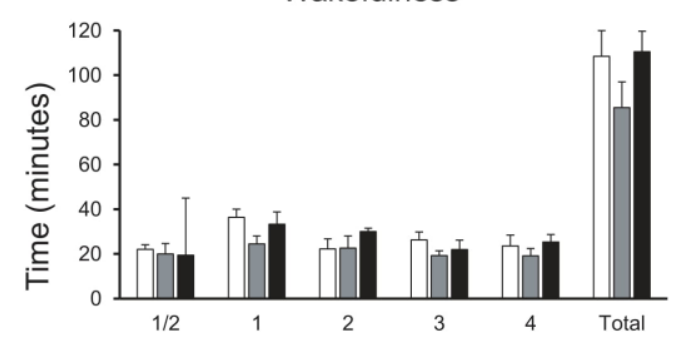

Intermediate Stage

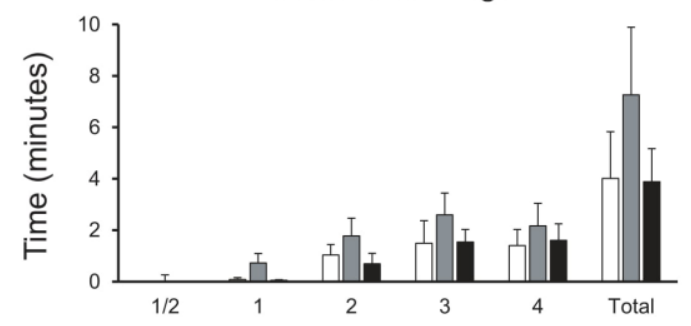

REM Sleep

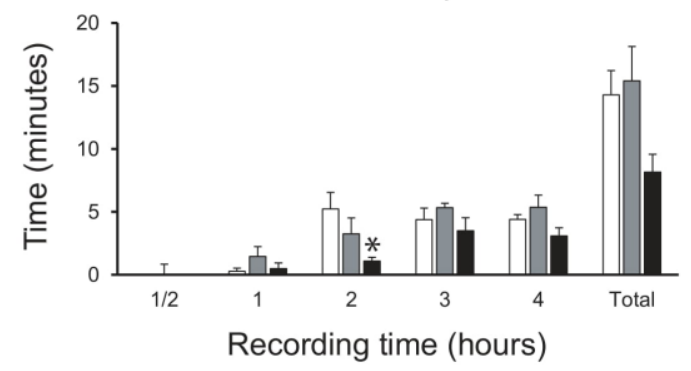

Light Sleep

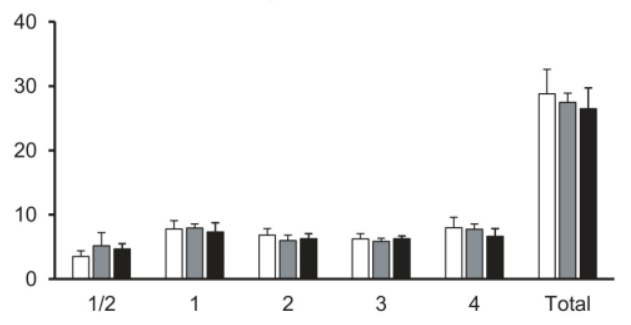

Slow Wave Sleep

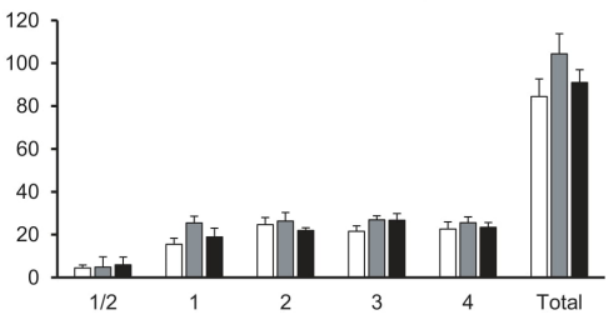

NREM Sleep

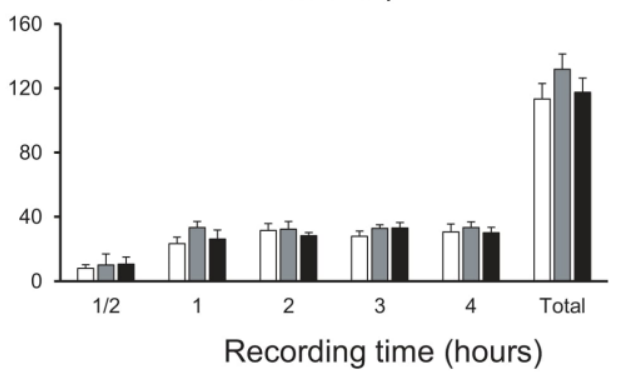

口 Saline $\quad$ BIC $10 \mathrm{ng} \quad \mathrm{BIC} 30 \mathrm{ng}$

Figure 3. Effects of bicuculline microinjections into the mPOA on sleep and wake parameters. Graphic charts show the mean \pm the standard error of the time spent in wakefulness, light sleep, slow wave sleep, no-REM sleep (NREM, light sleep + slow wave sleep), intermediate stage and REM sleep after local administration of saline and BIC (10 and $30 \mathrm{ng} / 0.2 \mu \mathrm{l})$ during the first half hour, each hour individually and the total recording time (four hours). Group differences were 
determined by one-way repeated measures ANOVA followed by Tukey as post hoc; Asterisk (*) indicates significant difference compared to control value.
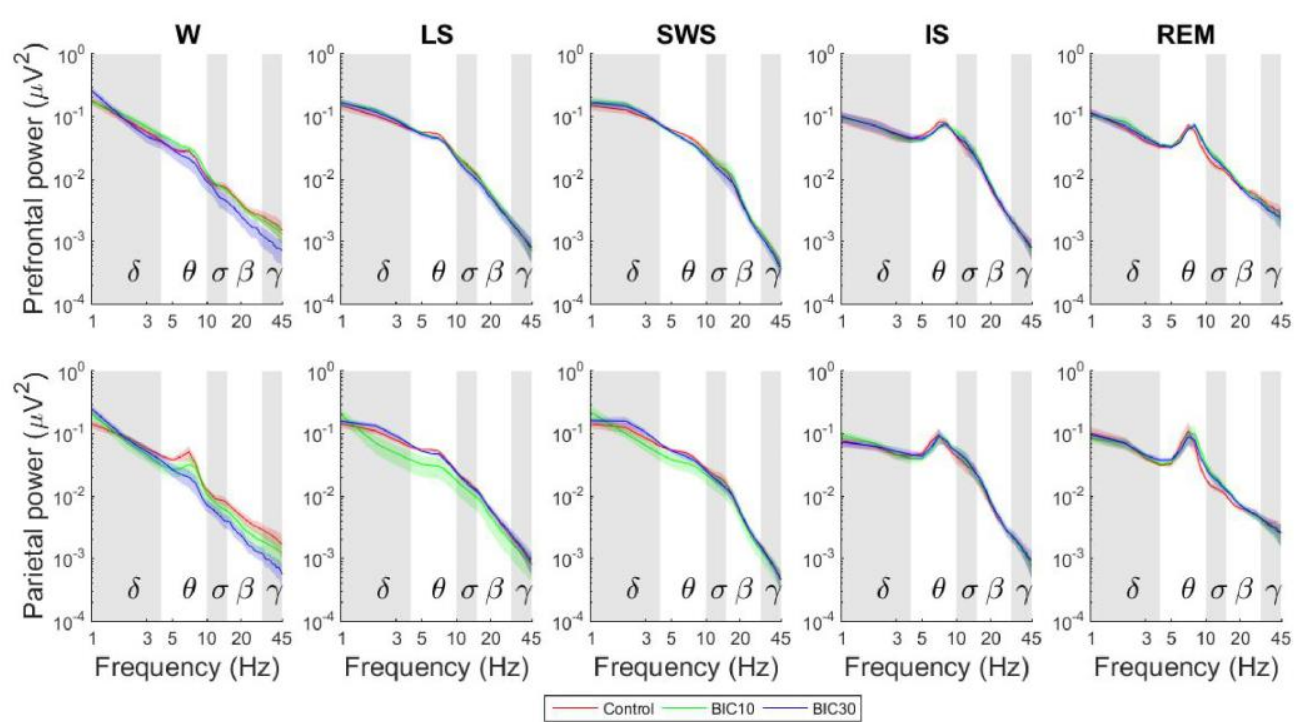

Figure 4. Mean relative power profile of each behavioral state during the entire recording time (4 hours) after bicuculline (BIC) treatment and vehicle within the mPOA. The graphs plot spectral power changes in the prefrontal and parietal regions for frequencies between 1 and $45 \mathrm{~Hz}$ during the different behavioral stages after BIC (10 and $30 \mathrm{ng} / 0.2 \mu \mathrm{l})$ or vehicle treatment. Thick and dark lines represent mean values and its correspondent standard error is represented in a shading of the same light color. Frequency bands are indicated by alternating horizontal-colored background of the graphs. Group differences were determined by one-way repeated measures ANOVA followed by Tukey as post hoc. No significant differences were found. W, wakefulness; LS, light sleep; SWS, slow wave sleep; REM, REM sleep. 

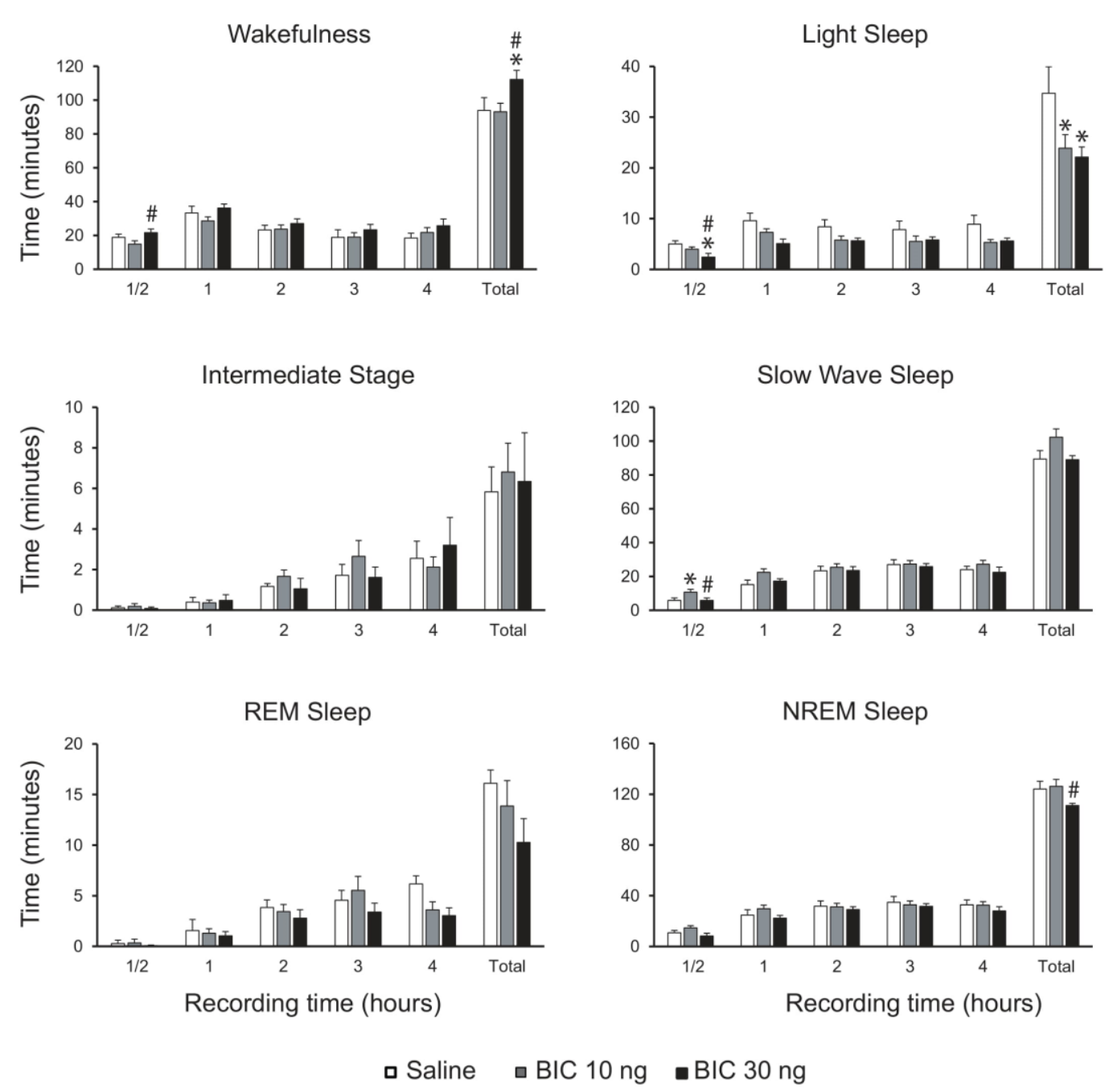

Figure 5. Effects of bicuculline microinjections into the VLPO on sleep and wake parameters. Graphic charts show the mean \pm the standard error of the time spent in wakefulness, light sleep, slow wave sleep, no-REM sleep (NREM, light sleep + slow wave sleep), intermediate stage and REM sleep after local administration of saline and BIC (10 and $30 \mathrm{ng} / 0.2 \mu \mathrm{l})$ during the first half hour, each hour individually and the total recording time (four hours). Group differences were determined by one-way repeated measures ANOVA followed by Tukey as post hoc; 
Asterisk (*) indicates significant differences compared to control values; numeral (\#) indicates significant differences compared to BIC10 ng.
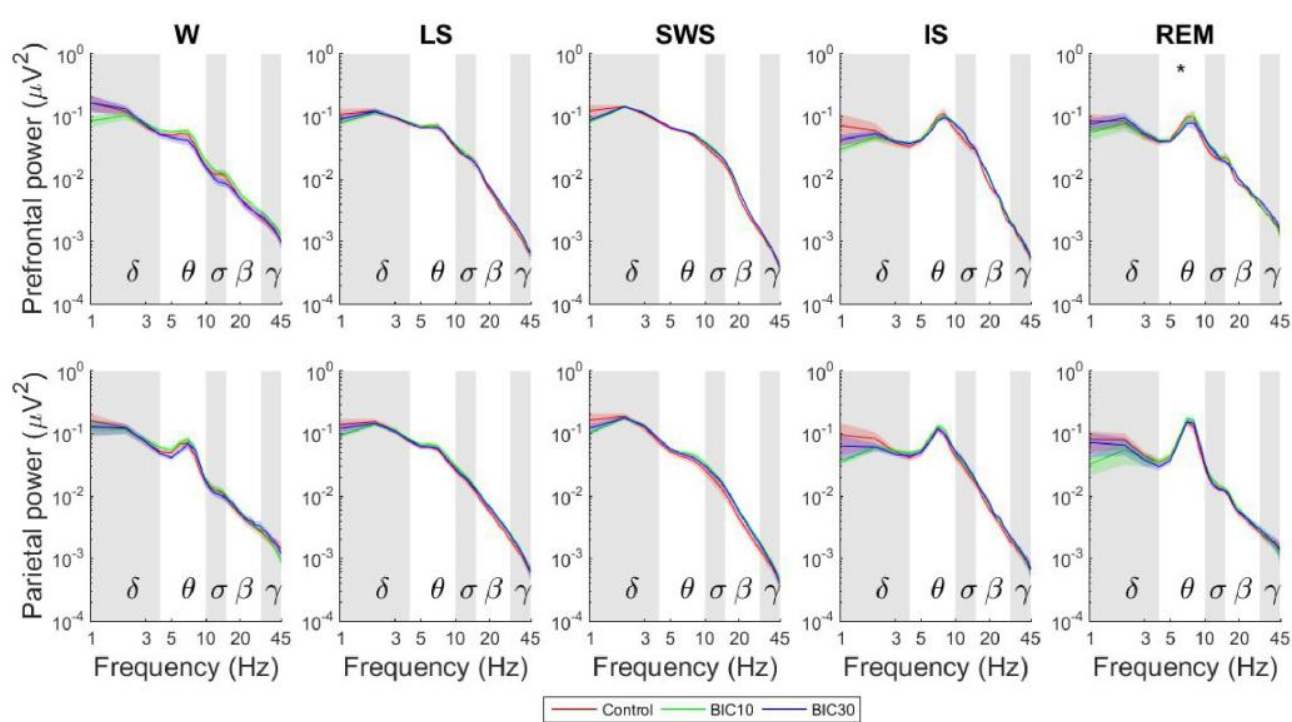

Figure 6. Mean relative power profile of each behavioral state during the entire recording time (4 hours) after bicuculline (BIC) treatment and vehicle within the VLPO. The graphs plot spectral power changes in the prefrontal and parietal regions for frequencies between 1 and $45 \mathrm{~Hz}$ during the different behavioral stages after BIC (10 and $30 \mathrm{ng} / 0.2 \mu \mathrm{l})$ or vehicle treatment. Thick and dark lines represent mean values and its correspondent standard error is represented in a shading of the same light color. Frequency bands are indicated by alternating horizontal-colored background of the graphs. Group differences were determined by one-way repeated measures ANOVA followed by Tukey as post hoc. Significant difference between BIC30 and control group is indicated by an asterisk ( $\left.{ }^{*}, p<0.05\right)$. W, wakefulness; LS, light sleep; SWS, slow wave sleep; REM, REM sleep. 
bioRxiv preprint doi: https://doi.org/10.1101/2021.04.08.439015; this version posted April 9, 2021. The copyright holder for this preprint (which was not certified by peer review) is the author/funder. All rights reserved. No reuse allowed without permission.

Table 1. Maternal behavior after BIC and saline microinjections into the

mPOA. Effects of bilateral microinjections of saline and BIC (10 and $30 \mathrm{ng} / 0.2$ $\mu \mathrm{l} /$ side) into the medial preoptic area (mPOA) on maternal behavior.

\begin{tabular}{lccc}
\hline & \multicolumn{3}{c}{ mPOA } \\
\hline Latency to (seconds): & Control & BIC $_{10}$ & BIC $_{30}$ \\
$\quad$ Reunion litter & $73.0 \pm 48.0$ & $34.0 \pm 107.0$ & $91.0 \pm 288.3$ \\
Hover over & $88.0 \pm 50.3$ & $141.0 \pm 109.5$ & $1241.0 \pm 728.8$ \\
$\quad$ Nursing & $261.0 \pm 100.3$ & $259.0 \pm 200.5$ & $1413.0 \pm 544.5^{*} \#$ \\
Duration (seconds) & & & \\
$\quad$ Hover over & $423.0 \pm 111.0$ & $347.0 \pm 107.8$ & $108.0 \pm 108.0^{*}$ \\
$\quad$ Nursing & $1174.0 \pm 156.0$ & $976.0 \pm 140.3$ & $425.0 \pm 323.3^{*} \#$ \\
Contact with pups & $1612.0 \pm 70.8$ & $1323.0 \pm 252.0$ & $614.0 \pm 490.5^{*}$ \\
Milk ejections (number) & $3.0 \pm 1.3$ & $2.0 \pm 1.8$ & $0.0 \pm 0.8^{*}$ \\
Litter weigh gain (\%) & $4.84 \pm 0.8$ & $5.0 \pm 0.5$ & $3.8 \pm 0.5$ \\
\hline
\end{tabular}

Group differences were determined by Friedman followed by Wilcoxon matched-pair signed-ranks test; significant differences compared to saline treatment are indicated by asterisks ( $\left.{ }^{*}, \mathrm{p}<0.05\right)$; significant differences compared to $\mathrm{BIC}_{10}$ treatment are indicated by numeral $(\#, p<0.05)$. 
Table 2. Sleep and waking effects after bicuculline (BIC) and saline microinjections into the medial preoptic area (mPOA). Effects of bilateral microinjections of saline and BIC (10 and $30 \mathrm{ng} / 0.2 \mu \mathrm{l} / \mathrm{side}$ ) into the mPOA on sleep parameters.

\begin{tabular}{|c|c|c|c|}
\hline & Control & $\mathrm{BIC}_{10}$ & $\mathrm{BIC}_{30}$ \\
\hline $\begin{array}{l}\text { Wakefulness } \\
\text { Number of episodes }\end{array}$ & $121.0 \pm 6.0$ & $120.3 \pm 6.3$ & $128.3 \pm 6.7$ \\
\hline $\begin{array}{l}\text { Episodes duration } \\
\text { (minutes) }\end{array}$ & $0.8 \pm 0.1$ & $0.71 \pm 0.1$ & $0.9 \pm 0.1$ \\
\hline $\begin{array}{l}\text { Frequency } \\
\text { (episodes/hour) }\end{array}$ & $33.1 \pm 3.2$ & $30.1 \pm 1.6$ & $32.1 \pm 1.7$ \\
\hline $\begin{array}{l}\text { Light Sleep (LS) } \\
\text { Number of episodes }\end{array}$ & $177.0 \pm 16.9$ & $185.7 \pm 5.0$ & $179.6 \pm 16.6$ \\
\hline $\begin{array}{l}\text { Episodes duration } \\
\text { (minutes) }\end{array}$ & $0.2 \pm 0.0$ & $0.2 \pm 0.0$ & $0.2 \pm 0.0$ \\
\hline $\begin{array}{l}\text { Frequency } \\
\text { (episodes/hour) }\end{array}$ & $47.7 \pm 4.4$ & $46.4 \pm 1.2$ & $44.9 \pm 4.1$ \\
\hline $\begin{array}{l}\text { Slow Wave Sleep } \\
\text { (SWS) } \\
\text { Number of episodes }\end{array}$ & $133.9 \pm 11.6$ & $162.4 \pm 7.9$ & $148.4 \pm 10.1$ \\
\hline $\begin{array}{l}\text { Episodes duration } \\
\text { (minutes) }\end{array}$ & $0.5 \pm 0.1$ & $0.6 \pm 0.0$ & $0.6 \pm 0.0$ \\
\hline $\begin{array}{l}\text { Frequency } \\
\text { (episodes/hour) }\end{array}$ & $36.0 \pm 2.9$ & $40.6 \pm 2.0$ & $37.1 \pm 2.5$ \\
\hline $\begin{array}{l}\text { Intermediate Stage } \\
\text { (IS) }\end{array}$ & & & \\
\hline $\begin{array}{l}\text { Number of episodes } \\
\text { Episodes duration } \\
\text { (minutes) }\end{array}$ & $\begin{array}{c}20.7 \pm 9.0 \\
0.2 \pm 0.0\end{array}$ & $\begin{array}{c}25.0 \pm 8.0 \\
0.3 \pm 0.0\end{array}$ & $\begin{array}{c}14.8 \pm 3.9 \\
0.3 \pm 0.0\end{array}$ \\
\hline $\begin{array}{l}\text { Frequency } \\
\text { (episodes/hour) }\end{array}$ & $5.2 \pm 2.3$ & $6.3 \pm 2.0$ & $2.9 \pm 0.9$ \\
\hline $\begin{array}{l}\text { REM Sleep } \\
\text { Number of episodes }\end{array}$ & $18.3 \pm 5.8$ & $17.6 \pm 2.3$ & $10.4 \pm 2.2$ \\
\hline
\end{tabular}


bioRxiv preprint doi: https://doi.org/10.1101/2021.04.08.439015; this version posted April 9, 2021. The copyright holder for this preprint (which was not certified by peer review) is the author/funder. All rights reserved. No reuse allowed without permission.

Episodes duration $\quad 1.0 \pm 0.2 \quad 0.9 \pm 0.1 \quad 0.9 \pm 0.1$

(minutes)

Frequency

$4.6 \pm 1.3$

$4.4 \pm 0.6$

$2.6 \pm 0.6$

(episodes/hour)

\section{Latency (minutes)}

$\begin{array}{lccc}\text { NREM } & 13.3 \pm 3.7 & 6.2 \pm 2.0 & 17.4 \pm 5.5 \\ \text { REM } & 75.2 \pm 9.6 & 75.1 \pm 14.4 & 100.6 \pm 22.1\end{array}$

Group differences were determined by repeated measures ANOVA. 
bioRxiv preprint doi: https://doi.org/10.1101/2021.04.08.439015; this version posted April 9, 2021. The copyright holder for this preprint (which was not certified by peer review) is the author/funder. All rights reserved. No reuse allowed without permission.

Table 3. Maternal behavior after BIC and saline microinjections into the

VLPO. Effects of bilateral microinjections of saline and BIC (10 and $30 \mathrm{ng} / 0.2$

$\mu \mathrm{l} / \mathrm{side}$ ) into the ventrolateral preoptic area (VLPO) on maternal behavior.

\begin{tabular}{lccc}
\hline & \multicolumn{3}{c}{ VLPO } \\
\hline Latency to (seconds): & Control & BIC $_{10}$ & BIC $_{30}$ \\
Reunion litter (sec) & $144.5 \pm 233.0$ & $189.0 \pm 262.9$ & $429.5 \pm 345.9$ \\
$\quad$ Hover over & $101.0 \pm 58.9$ & $508.5 \pm 271.5^{\star}$ & $671.5 \pm 120.6^{*}$ \\
$\quad$ Nursing posture & $295.0 \pm 82.0$ & $604.0 \pm 176.5^{\star}$ & $780.5 \pm 176.8^{*}$ \\
Duration of (seconds): & & & \\
$\quad$ Hover over & $493.5 \pm 113.1$ & $186.0 \pm 94.6^{*}$ & $181.0 \pm 77.0^{*}$ \\
$\quad$ Nursing postures & $1077.5 \pm 203.8$ & $1075.0 \pm 355.3$ & $861.0 \pm 583.0^{*}$ \\
$\quad$ Contact with pups & $1668.0 \pm 131.5$ & $1267.5 \pm 397.1^{*}$ & $1111.5 \pm 594.5^{*}$ \\
Milk ejections (number) & $2.0 \pm 0.25$ & $1.0 \pm 1.0$ & $1.5 \pm 1.1$ \\
Litter weight gain & $4.8 \pm 0.9$ & $5.4 \pm 0.8$ & $3.7 \pm 0.5$ \\
\hline
\end{tabular}

Group differences were determined by Friedman followed by Wilcoxon matchedpair signed-ranks test; significant differences compared to saline treatment are indicated by asterisks $\left({ }^{*}, p<0.05\right)$. 
bioRxiv preprint doi: https://doi.org/10.1101/2021.04.08.439015; this version posted April 9, 2021. The copyright holder for this preprint (which was not certified by peer review) is the author/funder. All rights reserved. No reuse allowed without permission.

Table 4. Sleep and waking effects after bicuculline (BIC) and saline microinjections into the ventrolateral preoptic area (VLPO). Effects of bilateral microinjections of saline and BIC (10 and $30 \mathrm{ng} / 0.2 \mu \mathrm{l} / \mathrm{side}$ ) into VLPO on sleep parameters.

\begin{tabular}{|c|c|c|c|}
\hline & Control & $\mathrm{BIC}_{10}$ & $\mathrm{BIC}_{30}$ \\
\hline $\begin{array}{l}\text { Wakefulness } \\
\text { Number of episodes }\end{array}$ & $143.9 \pm 11.7$ & $144.8 \pm 9.8$ & $148.1 \pm 13.3$ \\
\hline $\begin{array}{l}\text { Episodes duration } \\
\text { (minutes) }\end{array}$ & $0.66 \pm 0.1$ & $0.7 \pm 0.1$ & $0.8 \pm 0.1$ \\
\hline $\begin{array}{l}\text { Frequency } \\
\text { (episodes/hour) }\end{array}$ & $35.97 \pm 2.9$ & $36.2 \pm 2.3$ & $37.0 \pm 3.1$ \\
\hline $\begin{array}{l}\text { Light Sleep (LS) } \\
\text { Number of episodes }\end{array}$ & $203.3 \pm 19.8$ & $173.3 \pm 11.6$ & $169.0 \pm 13.0$ \\
\hline $\begin{array}{l}\text { Episodes duration } \\
\text { (minutes) }\end{array}$ & $0.2 \pm 0.0$ & $0.1 \pm 0.0^{*}$ & $0.1 \pm 0.0^{*}$ \\
\hline $\begin{array}{l}\text { Frequency } \\
\text { (episodes/hour) }\end{array}$ & $50.8 \pm 4.9$ & $43.3 \pm 2.7$ & $42.3 \pm 3.0$ \\
\hline $\begin{array}{l}\text { Slow Wave Sleep } \\
\text { (SWS) } \\
\text { Number of episodes }\end{array}$ & $148.9 \pm 11.7$ & $160.5 \pm 9.7$ & $150.4 \pm 8.3$ \\
\hline $\begin{array}{l}\text { Episodes duration } \\
\text { (minutes) }\end{array}$ & $0.6 \pm 0.1$ & $0.7 \pm 0.0$ & $0.6 \pm 0.0$ \\
\hline $\begin{array}{l}\text { Frequency } \\
\text { (episodes/hour) }\end{array}$ & $37.2 \pm 2.9$ & $40.1 \pm 2.3$ & $37.6 \pm 1.9$ \\
\hline $\begin{array}{l}\text { Intermediate Stage } \\
\text { (IS) }\end{array}$ & & & \\
\hline $\begin{array}{l}\text { Number of episodes } \\
\text { Episodes duration } \\
\text { (minutes) }\end{array}$ & $\begin{array}{c}26.2 \pm 4.5 \\
0.2 \pm 0.0\end{array}$ & $\begin{array}{c}28.1 \pm 5.4 \\
0.2 \pm 0.0\end{array}$ & $\begin{array}{c}19.9 \pm 4.8 \\
0.3 \pm 0.0\end{array}$ \\
\hline $\begin{array}{l}\text { Frequency } \\
\text { (episodes/hour) }\end{array}$ & $6.6 \pm 1.1$ & $7.0 \pm 1.3$ & $5.0 \pm 1.1$ \\
\hline $\begin{array}{l}\text { REM Sleep } \\
\text { Number of episodes }\end{array}$ & $22.8 \pm 2.6$ & $24.9 \pm 4.9$ & $12.8 \pm 2.8 \#$ \\
\hline
\end{tabular}


bioRxiv preprint doi: https://doi.org/10.1101/2021.04.08.439015; this version posted April 9, 2021. The copyright holder for this preprint (which was not certified by peer review) is the author/funder. All rights reserved. No reuse allowed without permission.
Episodes duration
$0.7 \pm 0.1$
$0.6 \pm 0.1$
$0.9 \pm 0.1$

(minutes)

Frequency

$5.7 \pm 0.5$

$6.2 \pm 1.1$

$3.2 \pm 0.6 \#$

(episodes/hour)

Latency (minutes)

NREM

$$
9.3 \pm 0.9
$$

$8.5 \pm 1.5$

$18.1 \pm 3.9 \#$

REM

$53.2 \pm 8.8$

$60.7 \pm 11.4$

$70.0 \pm 13.9$

Group differences were determined by repeated measures ANOVA followed by Tukey post hoc test; significant differences compared to saline treatment are indicated by asterisks ( ${ }^{*}, \mathrm{p}<0.05$ ); significant differences compared to $\mathrm{BIC}_{10}$ treatment are indicated by numeral $(\#, p<0.05)$. 